\title{
Antireflective coatings for the red camera of WEAVE spectrograph
}

R. Ortiz, E. Carrasco, G. Páez, J. Reyes, Andrea Hidalgo, et al.

R. Ortiz, E. Carrasco, G. Páez, J. Reyes, Andrea Hidalgo, Gavin Dalton, Scott Trager, J. Alfonso L. Aguerri, Piercarlo Bonifacio, Antonella Vallenari, Don Carlos Abrams, Kevin Middleton, "Antireflective coatings for the red camera of WEAVE spectrograph," Proc. SPIE 10706, Advances in Optical and Mechanical Technologies for Telescopes and Instrumentation III, 107065G (10 July 2018); doi: 10.1117/12.2313955

Event: SPIE Astronomical Telescopes + Instrumentation, 2018, Austin, Texas, United States 


\title{
ANTIREFLECTIVE COATINGS FOR THE RED CAMERA OF WEAVE SPECTROGRAPH
}

\author{
R. Ortiz*a, E. Carrasco ${ }^{\text {a }}$, G. Páez ${ }^{\mathrm{c}}$, J. Reyes ${ }^{\mathrm{a}}$, Andrea Hidalgo ${ }^{\mathrm{a}, \mathrm{c}}$, Gavin Dalton ${ }^{\mathrm{c}, \mathrm{d}}$, Scott Trager ${ }^{\mathrm{e}}$, J. \\ Alfonso L. Aguerrif ${ }^{\mathrm{f}}$, Piercarlo Bonifacio ${ }^{\mathrm{g}}$, Antonella Vallenari ${ }^{\mathrm{h}}$, Don Carlos Abrams ${ }^{\mathrm{i}}$ and Kevin \\ Middleton $^{\mathrm{d}}$

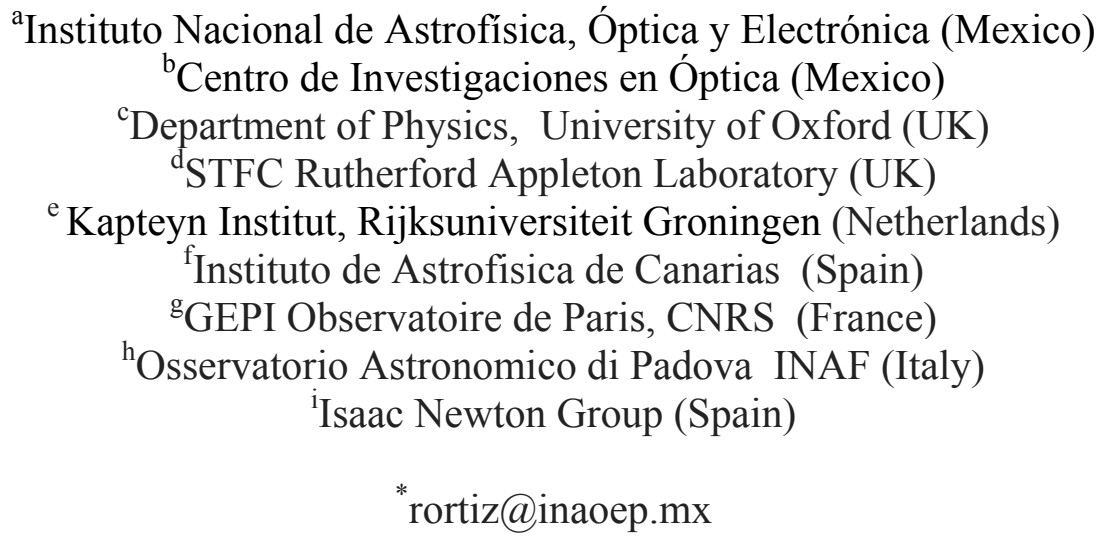

\begin{abstract}
In this work we present the coatings of the spectrograph red camera of WEAVE -the new multiobject survey facility for the $4.2 \mathrm{~m}$ William Herschel Telescope. The initial requirements of WEAVE red camera lenses, with reflectances as low as $0.4 \%$ through the wavelength interval from $590 \mathrm{~nm}$ to $959 \mathrm{~nm}$ at angles of incidence of $18^{\circ}+/-17^{\circ}$ represented a challenge for both design and production. Based on initial requirements, several solutions to the same problem were achieved and tested. The customized designs have been continuously improved through theoretical and experimental approximations. From transmittance measurements at normal incidence we developed a method to determine the reflectance at different angles of incidence. We show the designs and coating transmittance obtained for the four glasses on test runs to guarantee that the designs were achievable experimentally. Additionally, we present the reflectance obtained on the lenses of the the first four lenses of WEAVE red camera.
\end{abstract}

Keywords: Antireflective coatings, spectrographs

*rortiz@inaoep.mx phone+52 2222663100 


\section{INTRODUCTION}

WEAVE, acronyms of WHT Enhanced Area Velocity Explorer, is the new prime focus survey facility for the 4.2m WHT. In Dalton et al. [1] [2] an extensive description of the whole instrument is presented. A fibre positioning system will distribute along the $2^{\circ}$ diameter field of view almost $\sim 1000$ objects simultaneously, 20 small integral field units (IFUs) of 11" x 12" (1.3" spaxels) each or a large IFU that covers a 1.3' x 1.5' (2.6" spaxels) field of view. WEAVE spectrograph will offer spectral resolutions R 5800 in the wavelength interval of $366-959 \mathrm{~nm}$ and high resolution R 21000 in the ranges $404-465 \mathrm{~nm}, 473-545 \mathrm{~nm}$ and $595-685 \mathrm{~nm}$. The spectrograph is formed by a collimator mirror, a dichroic that directs the light to a blue and a red camera. The dispersive elements are volume phase holographic gratings. The 8 lenses of the cameras are identical except for the coatings optimized for the 366 to $606 \mathrm{~nm}$ and $579-959 \mathrm{~nm}$ wavelength intervals respectively. The first lens is an aspheric while the other seven are spheric, all of them of large aperture, with diameters between $195 \mathrm{~mm}$ to $320 \mathrm{~mm}$, and high optical accuracy. The spectrograph optical design was carried out at RALSpace. The spectrograph mechanical structure is in progress at NOVA. The 660 $\mathrm{mm}$ diameter mirror and the 14 spherical lenses of both cameras are being manufactured at INAOE in Mexico. In Izazaga et al. [3][4] detailed descriptions of the collimator and camera lenses manufacturing process are described. Here we discuss the design of the antireflective (AR) coatings to fulfill the requirements. The coating designs and deposition processes were carried out in a collaborative squeme between INAOE and CIO. INAOE provided the designs and discuss the expected performance with the CIO team as the depositions were carried out at their lab.

\subsection{AR coating specifications}

The antireflective coating specification was: Reflectance $\mathrm{R}_{\text {average }}<0.3 \%$ (goal $0.2 \%$ ), $\mathrm{R}_{\text {absolute }}<0.4 \%(0.3)$ for an angle of incidence (AOI) between 0 and $35^{\circ}$, for a wavelength interval between 366 and $606 \mathrm{~nm}$ and 5790 to $9590 \mathrm{~nm}$ for the blue and red cameras respectively.

The optical quality requirements of the WEAVE spherical camera lenses are described in Izazaga et al. [2] and Hidalgo et al. [5]. In Table 1 the lenses main characteristics relevant to the coatings are presented. The largest diameter is 320 $\mathrm{mm}$ where the AR coatings must fulfill the requirements in Reflectance and adherence. For each camera, the coating designs where developed for four substrates: PBL1Y, S-FPL51, PBM2Y and SLAL-9.

Table 1. WEAVE camera lenses main characteristics.

\begin{tabular}{|c|c|c|c|c|c|c|c|}
\hline $\begin{array}{c}\text { Camera } \\
\text { Blue / Red }\end{array}$ & $\begin{array}{c}\text { Material } \\
\text { Ohara }\end{array}$ & $\begin{array}{c}\text { Units }(\mathrm{mm}) \\
\text { Edge } \varnothing \\
\end{array}$ & $\begin{array}{l}\text { Left Surf. } \\
\text { Coated } \varnothing \\
\end{array}$ & C.A. Ø & $\begin{array}{r}\text { Right Surf. } \\
\text { Coated } \varnothing \\
\end{array}$ & C. A. $\varnothing$ & $\begin{array}{c}\text { Weight } \\
\text { (kg) }\end{array}$ \\
\hline Lens 2 & PBL1Y & 304 & 298 & 288.4 & 301.0 & 294.4 & 7.7 \\
\hline Lens 3 & S-FPL51 & 320 & 316 & 306.3 & 313.0 & 302.5 & 10.2 \\
\hline Lens 4 & PBL1Y & 320 & 310 & 299.8 & 292.0 & 282.4 & 14.4 \\
\hline Lens 5 & S-FPL51 & 298 & 296 & 288.4 & 296.0 & 288.2 & 8.8 \\
\hline Lens 6 & PBM2Y & 260 & 255 & 245.4 & 234.0 & 224.0 & 13.1 \\
\hline Lens 7 & PBM2Y & 238 & 222 & 212.3 & 182.0 & 172.4 & 13.0 \\
\hline Lens 8 & S-LAL9 & 195 & 172 & 162.3 & 168.6 & 162.6 & 3.0 \\
\hline
\end{tabular}

The main characteristics of these materials according to Ohara catalogue related to the coating design and deposition are shown in Table 2. The transmission properties of the coating depend mainly of the glass refractive index, the refractive index of the coating layers, the layers thickness and of the angle of incidence of the light into optical surface. The coatings are designed to produce that the relative phase change between the reflective beam in the border of the layer is $180^{\circ}$. When this condition is fulfilled destructive interference is produced between the two reflected beams before reaching the interface between the two mediums. There are single layer or multilayer AR coating that provide a very high efficiency in a reduced wavelength interval and AOI. The real challenge is to have high efficiency for a wide wavelength interval for a large range of AOI. 
In the AR coating design there is always a trade-off between the number of layers, the AOI and the wavelength interval. Several possible solutions were studied.

Table 2. Main properties of the glasses of WEAVE camera lenses relevant to the coatings.

\begin{tabular}{|c|c|c|c|c|c|}
\hline & S-FPL51 & S-LAL9 & PBL1Y & PBM2Y & Properties \\
\hline Nd & 1.497 & 1.691 & 1.548 & 1.620 & Index of refraction \\
\hline CTE $\left(10^{-7} /{ }^{\circ} \mathrm{C}\right)$ & & & & & $\begin{array}{c}\text { Linear coefficients of } \\
\text { thermal expansion }\end{array}$ \\
\hline$-30 \sim+70^{\circ} \mathrm{C}$ & 131 & 61 & 93 & 86 & \\
\hline $100 \sim+300^{\circ} \mathrm{C}$ & 155 & 74 & 106 & 97 & \\
\hline
\end{tabular}

\subsection{AR coating AOI specification}

A detailed analysis was carried out regarding the AOI specification of the cameras coatings. Based in Zemax ray tracing, RAL Space provided histograms of the AOI of different rays at each interface air/glass for the spherical camera lenses. Based on these histograms an statistics analysis was carried out. The histograms are in Figure 1 and the statistics summary is shown in Table 3. Where: Interval Max is the highest bar on the histogram. Highest number of hits; Average $C V$ is the average calculated by considering the central value of the bar rank. Hits have the central value; Average Min is the average calculated by considering the minimum value of the bar rank. Hits have the minimum value; Average Max is the average calculated by considering the maximum value of the bar rank. Hits have the maximum value; Average is the average of Average CV, Average Min and Average Max; and $S D$ is the standard deviation of the average, not the sample.

Table 3. Histograms data of the number of rays that hit each surface of the camera lenses at different AOI intervals.

\begin{tabular}{|c|c|c|c|c|c|c|c|c|}
\hline Element & Surface & \# hits & Interval Max $\left(^{\circ}\right)$ & Average $\mathrm{CV}\left({ }^{\circ}\right)$ & Average Min $\left(^{\circ}\right)$ & Average $\operatorname{Max}\left({ }^{\circ}\right)$ & Average $\left(^{\circ}\right)$ & SD \\
\hline \multirow{2}{*}{ Lens 2} & \begin{tabular}{|l} 
Right \\
\end{tabular} & 73660 & $21-24$ & 18.0 & 16.5 & 19.5 & 18.0 & 1.5 \\
\hline & Left & 72850 & $12-15$ & 15.0 & 13.5 & 17.0 & 15.2 & 1.7 \\
\hline \multirow{2}{*}{ Lens 3} & Right & 72800 & $15-18$ & 13.1 & 11.6 & 14.6 & 13.1 & 1.5 \\
\hline & Left & 73900 & $12-15$ & 14.7 & 13.2 & 16.2 & 14.7 & 1.5 \\
\hline \multirow{2}{*}{ Lens 4} & Right & 73600 & $12-15$ & 17.0 & 15.5 & 20.9 & 17.8 & 2.8 \\
\hline & Left & 73600 & $15-18$ & 14.1 & 12.6 & 15.6 & 14.1 & 1.5 \\
\hline \multirow{2}{*}{ Lens 5} & Right & 72900 & $18-21$ & 15.2 & 13.7 & 16.7 & 15.2 & 1.5 \\
\hline & Left & 73050 & $12-15$ & 14.6 & 13.1 & 16.4 & 14.7 & 1.6 \\
\hline \multirow{2}{*}{ Lens 6} & Left & 73100 & $6-9$ & 8.7 & 7.2 & 10.2 & 8.7 & 1.5 \\
\hline & Right & 74250 & $15-18$ & 16.2 & 14.7 & 17.7 & 16.2 & 1.5 \\
\hline \multirow{2}{*}{ Lens 7} & Right & 71950 & $12-15$ & 11.7 & 10.2 & 13.2 & 11.7 & 1.5 \\
\hline & Left & 72350 & $15-18$ & 13.7 & 12.2 & 15.2 & 13.7 & 1.5 \\
\hline \multirow{2}{*}{ Lens 8} & Right & 72100 & $9-12$ & 13.0 & 11.5 & 14.5 & 13.0 & 1.5 \\
\hline & Left & 73650 & $12-15$ & 15.6 & 14.1 & 17.2 & 15.7 & 1.5 \\
\hline \multicolumn{9}{|c|}{$\begin{array}{l}\text { Interval Max: highest bar on the histogram. Highest numer of hits. } \\
\text { Average CV: average calculated by considering the central value of the bar rank. Hits have the central value. } \\
\text { Average Min: average calculated by considering the minimum value of the bar rank. Hits have the minimum value. } \\
\text { Average Max: average calculated by considering the maximum value of the bar rank. Hits have the maximum value. } \\
\text { Average: average of Average CV, Average Min and Average Max }\end{array}$} \\
\hline
\end{tabular}



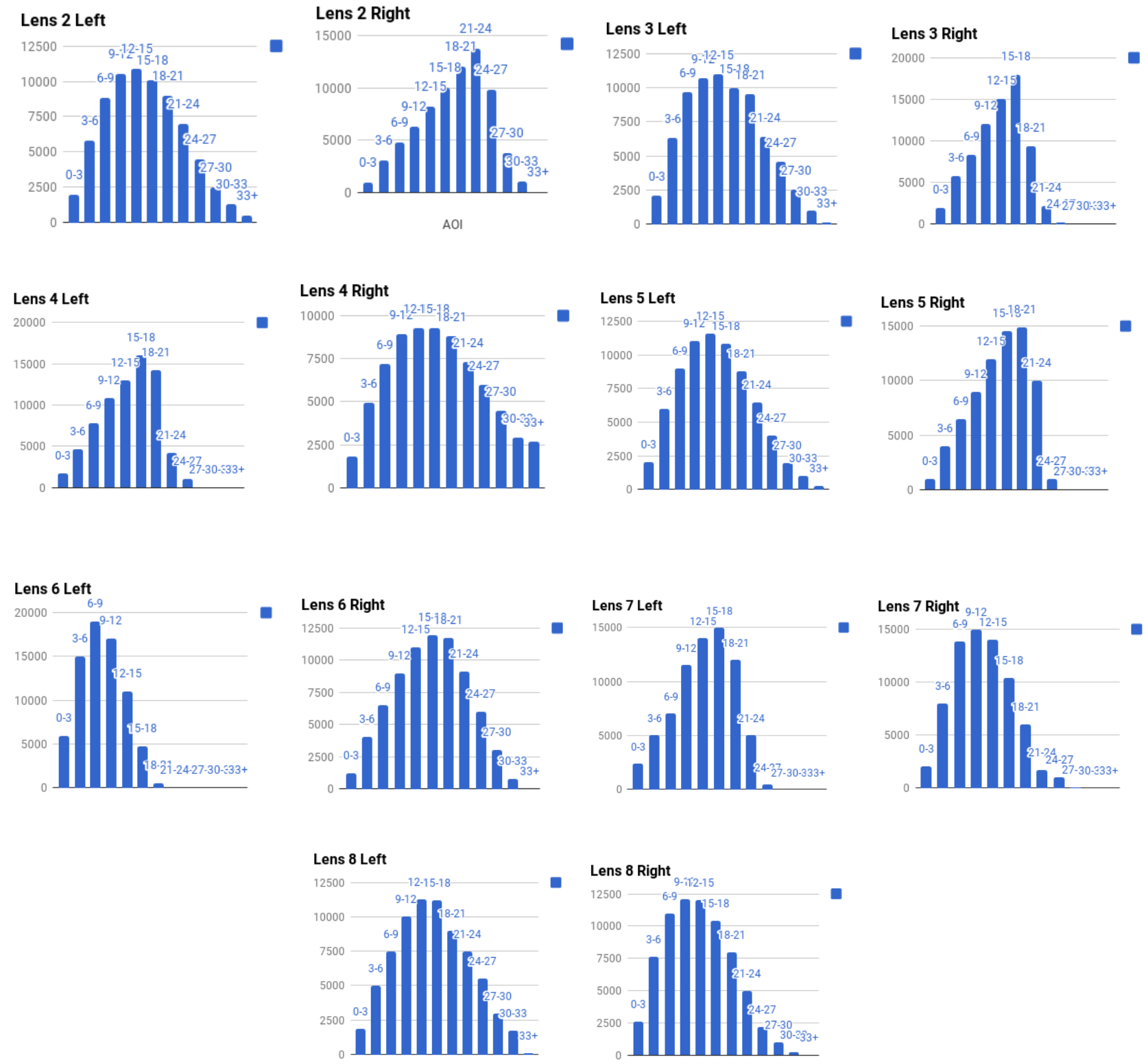

Figure 1. Histograms of number of rays hitting the indicated lens surface at different AOI bins.

From Table 3, it can be seen that there is a wide range of AOIs. The Interval Max values vary between $6^{\circ}$ and $24^{\circ}$, the Average $C V$ between $8.7^{\circ}$ and $18^{\circ}$, Average Min between $7.2^{\circ}$ and $16.5^{\circ}$, Average Max in $10.2^{\circ}-20.9^{\circ}$, Average values between 8.7 and $18^{\circ}$. However, looking at the histograms is clear that are less number of rays at angles larger that $21^{\circ}$. We decided to study the WEAVE case optimizing the coating between 0 and $20^{\circ}$ and between $0^{\circ}$ and $35^{\circ}$, but to analyze the coating performance at $0^{\circ}, 10^{\circ}, 20^{\circ}$, and $35^{\circ}$ in both cases. 


\section{DESIGNS}

Several designs were developed and the advantages of each were evaluated. Here we report the designs chosen as the best option in terms of performance and manufacturing. The teams of INAOE and CIO collaborated very closely to achieve the best solutions. The designed presented here are based in five layers of three materials $\mathrm{Ta} 2 \mathrm{O} 5, \mathrm{SiO} 2$ and $\mathrm{MgF} 2$.

\subsection{FIVE LAYERS COATINGS Ta2O5, SiO2 and MgF2}
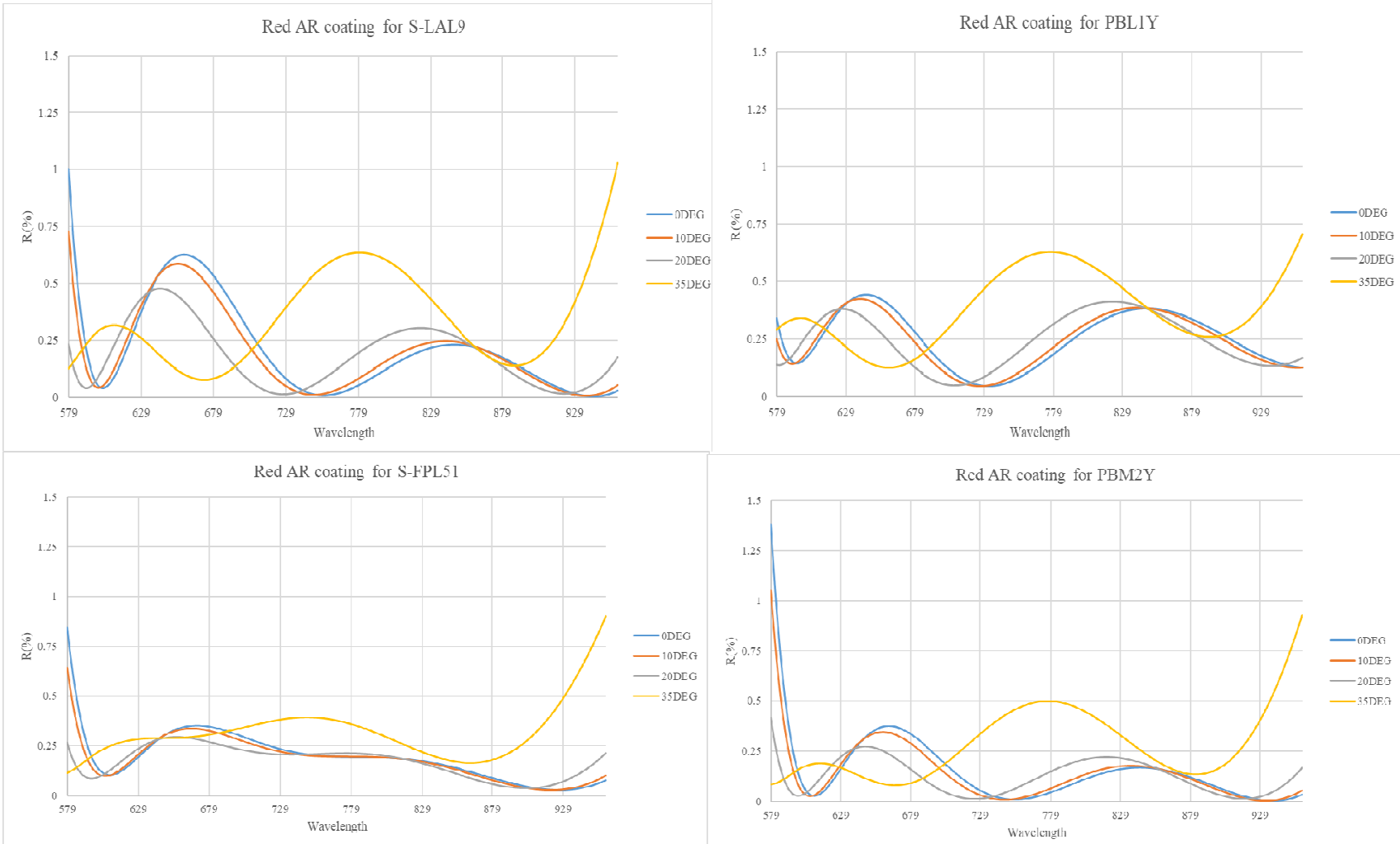

Figure 2. Reflectance for the four glasses of the red camera. Five-layers designs.

Table 4. Reflectance for different AOIs for the 5-layers coating designs.

\begin{tabular}{|c|c|c|c|c|c|c|c|c|}
\hline \multirow[t]{2}{*}{ AOI $\left(^{\circ}\right)$} & \multicolumn{2}{|c|}{$\begin{array}{l}\text { Reflectance (\%) } \\
\text { PBM2Y }\end{array}$} & \multicolumn{2}{|c|}{ S-LAL9 } & \multicolumn{2}{|c|}{ S-FPL51 } & \multicolumn{2}{|c|}{ PBL1Y } \\
\hline & Ave & Max & Ave & Max & Ave & Max & Ave & Max \\
\hline 0 & 0.14 & 0.80 & 0.21 & 1.00 & 0.19 & 0.85 & 0.25 & 0.44 \\
\hline 10 & 0.13 & 0.61 & 0.19 & 0.72 & 0.18 & 0.64 & 0.24 & 0.43 \\
\hline 20 & 0.12 & 0.24 & 0.18 & 0.48 & 0.17 & 0.29 & 0.24 & 0.41 \\
\hline 35 & 0.28 & 0.88 & 0.34 & 1.03 & 0.32 & 0.90 & 0.37 & 0.71 \\
\hline
\end{tabular}




\subsection{SIX LAYERS COATINGS Ta2O5, SiO2 and MgF2}
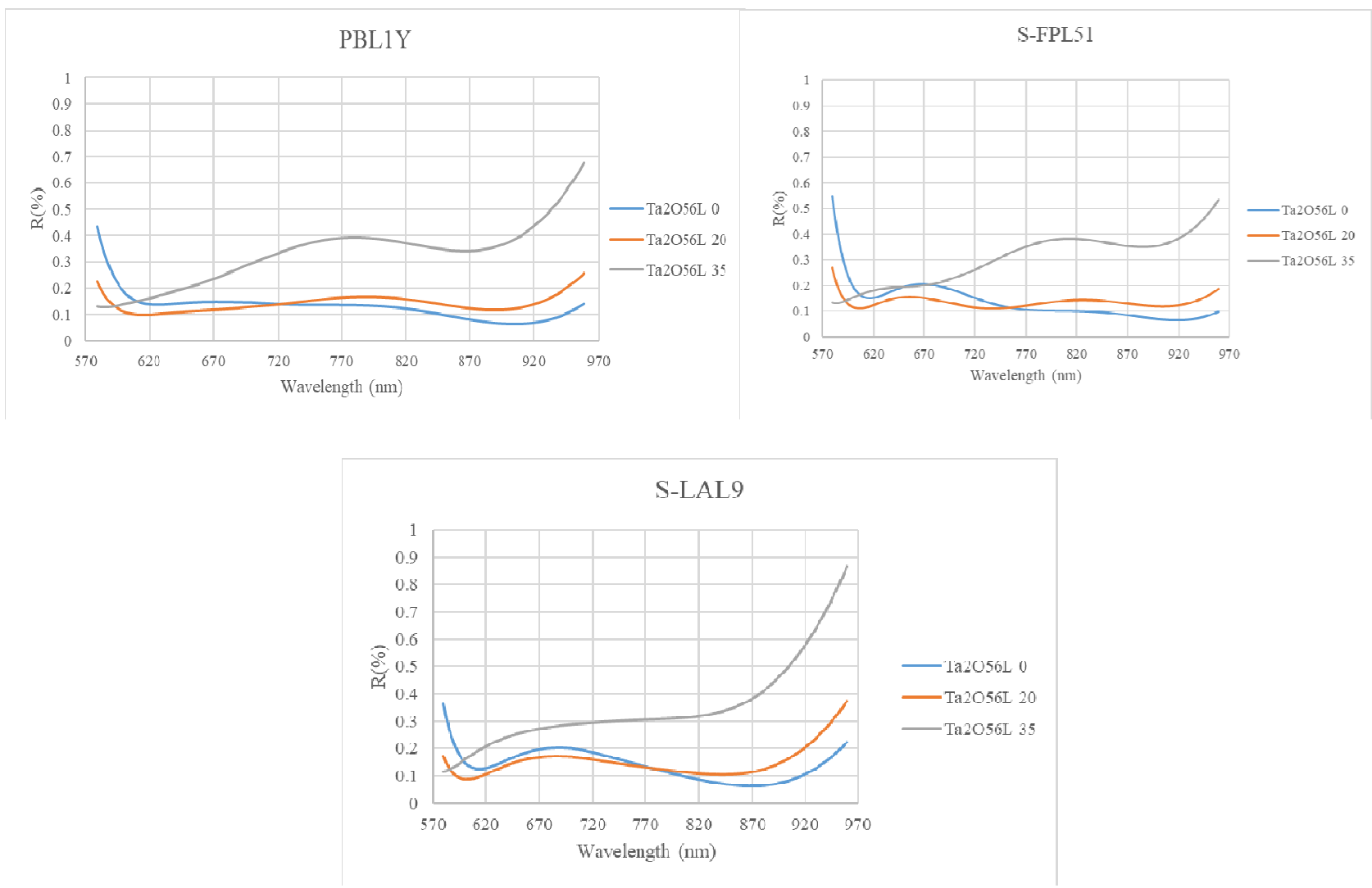

Figure 3. Reflectance of three glasses of the red camera. Six-layers designs.

Table 4. Reflectance for different AOIs for the 6-layers coating designs.

\begin{tabular}{|c|c|c|c|c|c|c|}
\hline AOI $\left(^{\circ}\right)$ & \multicolumn{6}{|c|}{ Reflectance (\%) } \\
\hline & Ave & Max & Ave & Max & Ave & Max \\
\hline 0 & 0.13 & 0.43 & 0.14 & 0.55 & 0.21 & 0.49 \\
\hline 20 & 0.14 & 0.26 & 0.13 & 0.27 & 0.20 & 0.29 \\
\hline 35 & 0.33 & 0.68 & 0.30 & 0.53 & 0.36 & 0.47 \\
\hline
\end{tabular}

\section{TEST RUNS DATA}

The coating evaporations were performed at CIO in the Integrity 39 Denton Vacuum Deposition System. In all the depositions at least a witness samples is included to evaluate the coating quality by measuring afterwards the transmittance of the sample(s). The instrument used for this measurement is a spectrophotometer UV-VIS PerkinElmer ${ }^{\circledR}$ Lambda 12, calibrated against patterns of the Mexican metrology entity CENAM. The spectrophotometer is at CIO metrology laboratory. Here we present the Reflectance derived from the transmittance measurement for witness samples of the same camera glasses shown in Table 1 and 2. For each sample three transmittance measurements are performed and the average is used for the rest of the calculations. 
From the transmittance witness sample data, it is required to remove the Fresnel losses due to the interface glass/air of the uncoated surface and the absorption losses due to the thickness of the witness sample. The principle is the following: the actual thickness of a given sample is modelled in Zemax considering an ideal coating of $99.9 \%$ transmittance at an AOI of $0^{\circ}$ on one surface and the other surface uncoated. Zemax provides values at specific wavelengths. The transmittance of the ideal coating is divided by the data measurements obtained at normal incidence. Once the mentioned effects are removed, the reflectance of the witness sample can be calculated as $\mathrm{R}=1-\mathrm{T}$ where $\mathrm{T}$ is the transmittance.

These calculations are straightforward if the measured transmittance is very close to the design one. In practice there are variations related to several parameters during the evaporation process resulting in difference between the thickness of the actual coating layers and the design.

To be able to calculate the reflectance at other AOI it is indispensable to find the design corresponding to the actual reflectance measured experimentally. A re-optimization through damped least squares of the design is done, using the experimental data as boundary to fit a theoretical model. In this way we can predict the actual coating behaviour at greater AOIs. This type of analysis aids also in estimating the error in the thickness of each layer, providing insight of the process of deposition itself.

\subsection{Example of the data analysis}
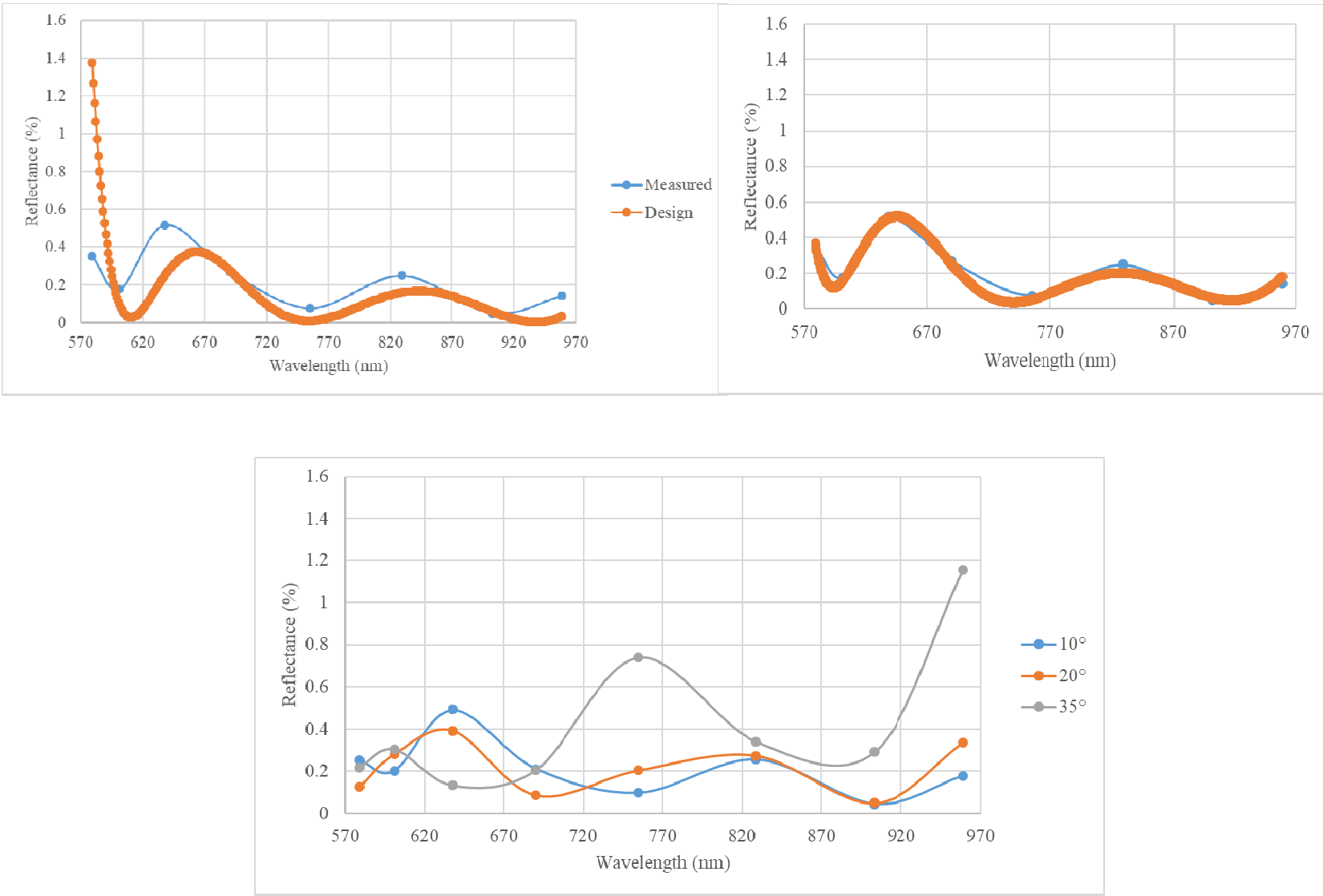

Figure 4. Top left: experimental data and theoretical reflectance, after removing Fresnel reflections from the second surface. Top right: Re-optimized design that fits the experimental data. Bottom: data extrapolation to non-normal AOI.

Figure 4 shows the data analysis process, the measurements of transmission are obtained experimentally, Fresnel effects are removed, the resulting curve is compared to the theoretical reflectance based on the AR design. The initial design is 
modified to match the experimental data by a re-optimization. Finally, the experimental data can be extrapolated to alternative AOIs based on the theoretical model.

\subsection{REPEATIBILITY}

CIO has worked intensively to characterize the Integrity 39 Denton Vacuum Deposition System. There are several factors. In Figure 5 we show the reflectance results for two PBM2Y witness samples in two different depositions for the same coating prescription. Samples L62 y L64 were coated in the first run and L63 y L65 in the second one. In Table 5 the average reflectance for different angles of incidence is reported. These results include all the experimental and measurements errors.

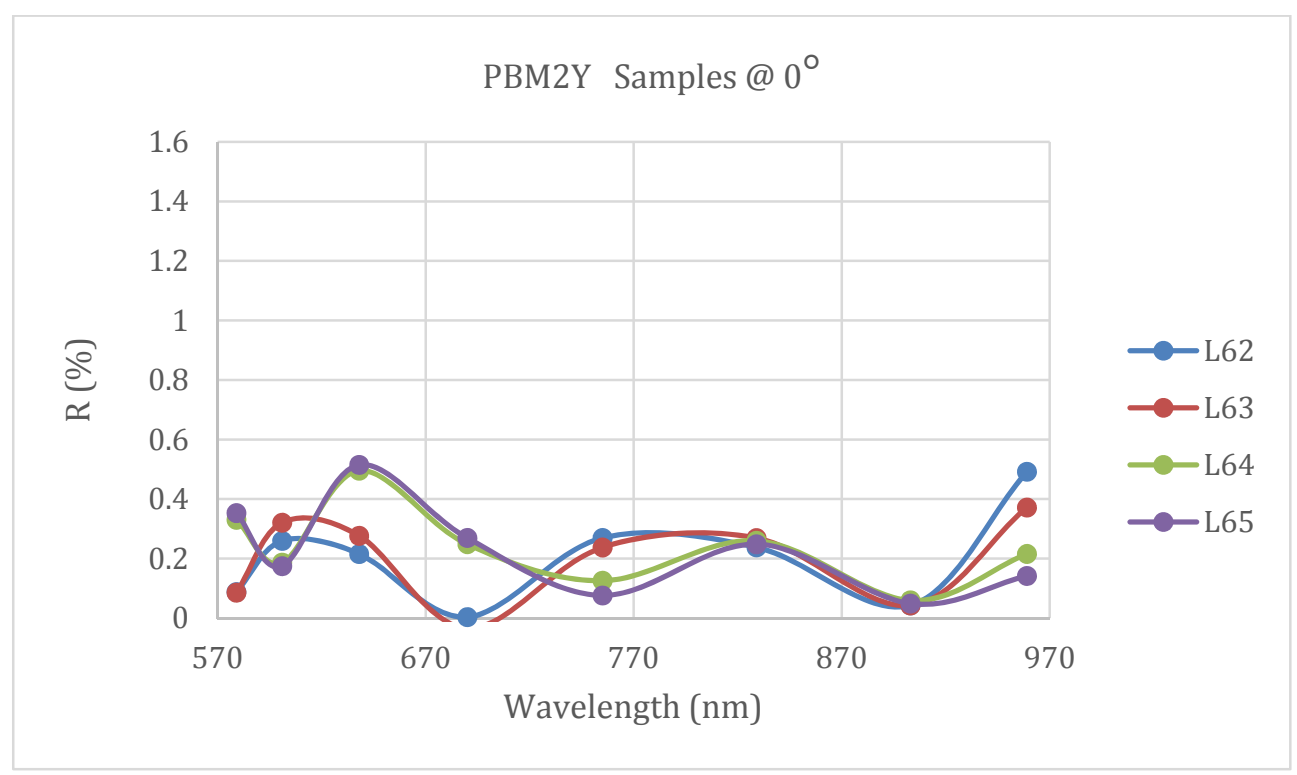

Figure 5. Reflectance obtained in different coating runs.

Table 5. Average reflectance obtained in two different runs for the same coating design.

\begin{tabular}{|c|c|c|c|c|}
\hline Sample & \multicolumn{4}{|c|}{ Average R (\%) } \\
\hline & $0^{\circ}$ & $10^{\circ}$ & $20^{\circ}$ & $35^{\circ}$ \\
\hline L62 & 0.20 & 0.21 & 0.26 & 0.56 \\
\hline L63 & 0.20 & 0.21 & 0.26 & 0.55 \\
\hline L64 & 0.24 & 0.23 & 0.24 & 0.47 \\
\hline L65 & 0.23 & 0.22 & 0.22 & 0.42 \\
\hline
\end{tabular}




\section{FINAL COATINGS}

\subsection{LENS 6 AND LENS 7 (PBM2Y)}

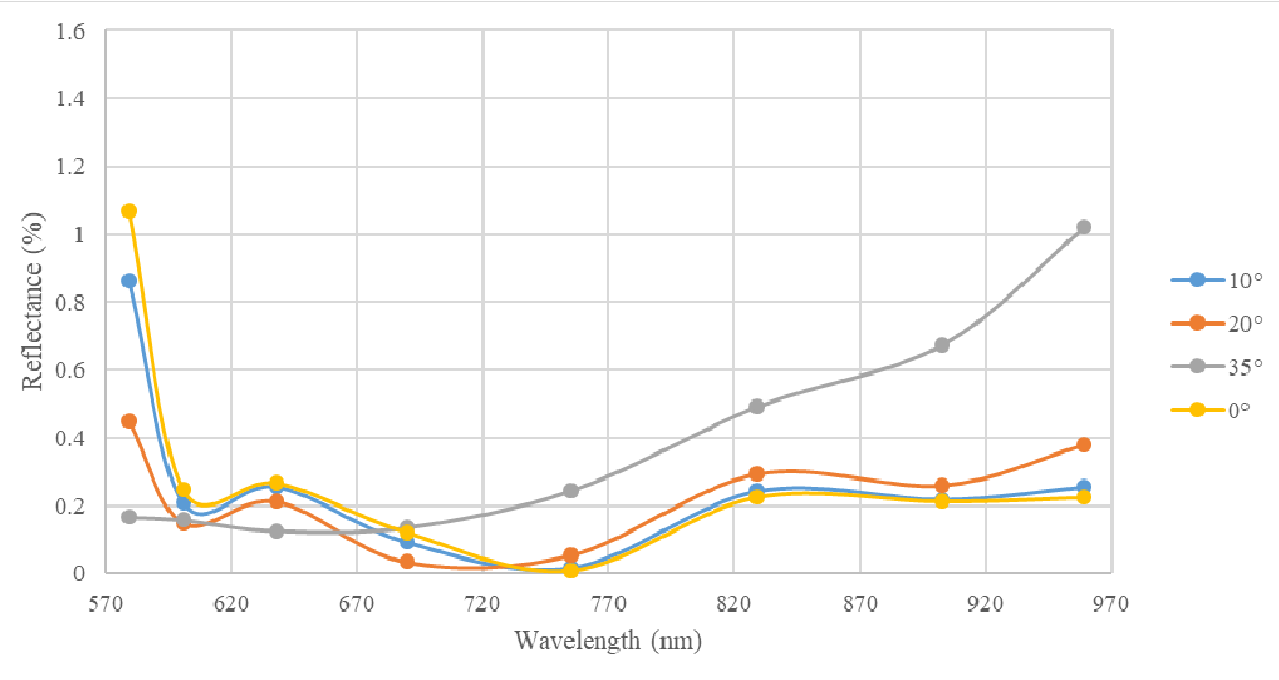

Figure 6. Reflectance obtained for PBM2Y Lens 6 and Lens 7. Surface 1.

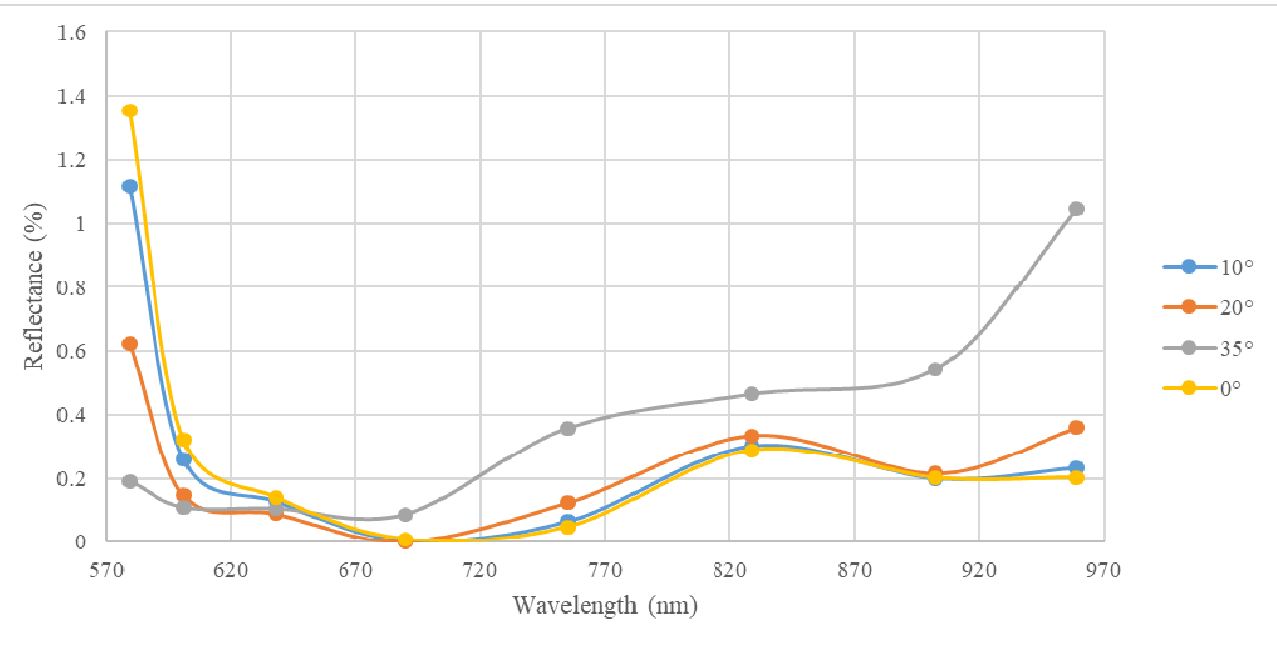

Figure 7. Reflectance obtained for PBM2Y Lens 6 and Lens 7. Surface 2.

Table 6. Average reflectance obtained for Lens 6 and Lens 7.

\begin{tabular}{|c|c|c|c|c|}
\hline \multirow{2}{*}{ AOI } & \multicolumn{4}{|c|}{ Reflectance (\%) } \\
\cline { 2 - 5 } & \multicolumn{2}{|c|}{ Surface 1 } & \multicolumn{2}{c|}{ Surface 2 } \\
\cline { 2 - 5 } & Ave & Max & Ave & Max \\
\hline 0 & 0.29 & 1.07 & 0.32 & 1.35 \\
\hline 10 & 0.27 & 0.86 & 0.29 & 1.12 \\
\hline 20 & 0.23 & 0.45 & 0.23 & 0.62 \\
\hline 35 & 0.38 & 1.02 & 0.36 & 1.04 \\
\hline
\end{tabular}




\subsection{LENS 4 (PBL1Y)}

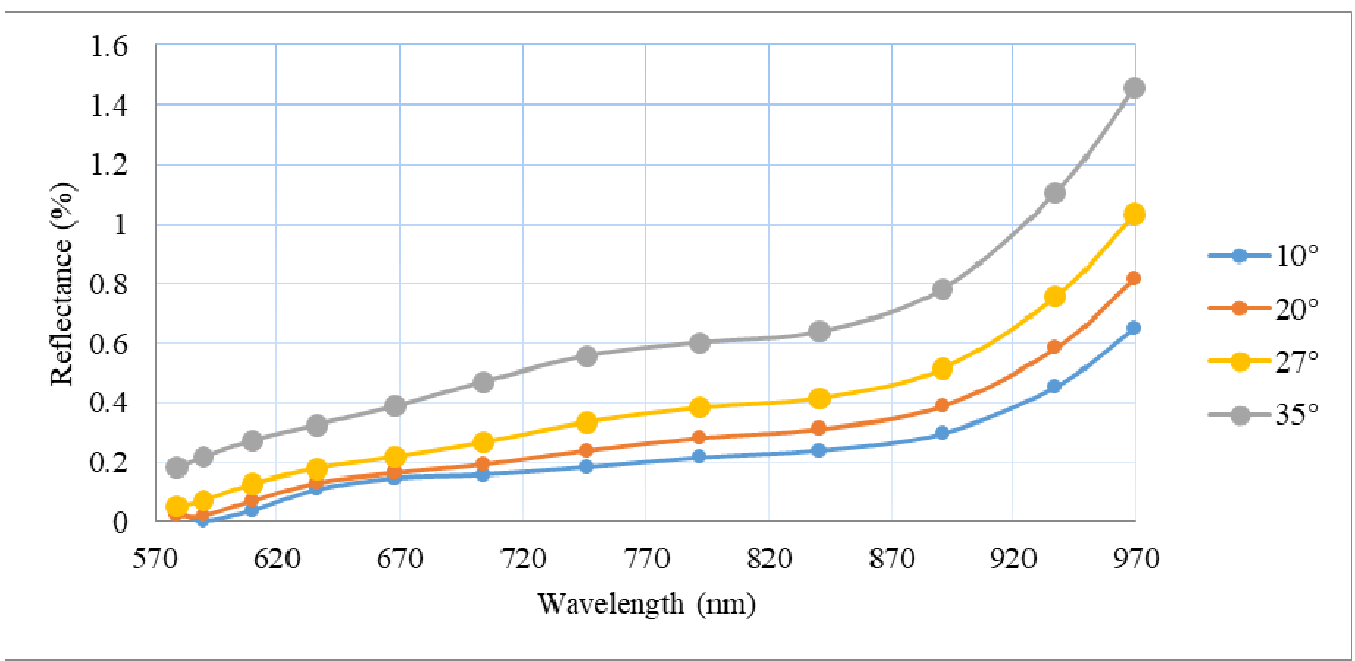

Figure 8. Reflectance obtained for PBL1Y Lens 4. Surface 1

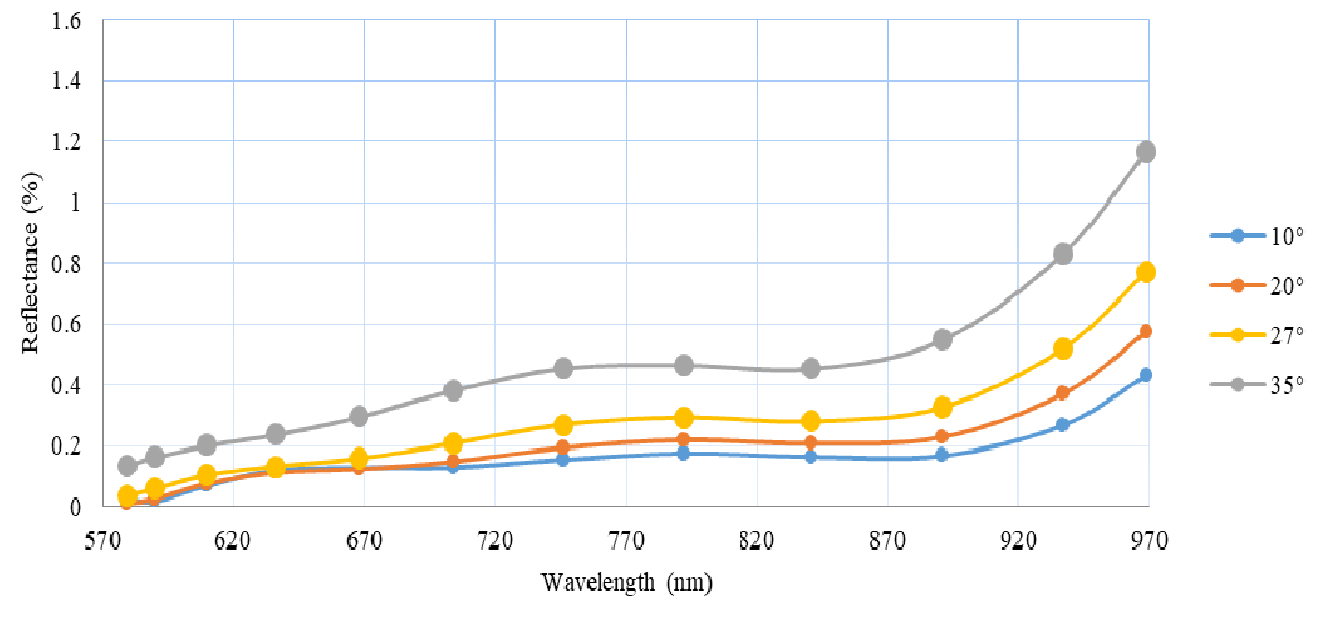

Figure 8. Reflectance obtained for PBL1Y Lens 4. Surface 2.

Table 7. Average reflectance obtained for Lens 4.

\begin{tabular}{|c|c|c|c|c|}
\hline \multirow{2}{*}{ AOI } & \multicolumn{4}{|c|}{ Reflectance (\%) } \\
\cline { 2 - 5 } & \multicolumn{2}{|c|}{ Surface 1 } & \multicolumn{2}{c|}{ Surface 2 } \\
\cline { 2 - 5 } & Ave & Max & Ave & Max \\
\hline 10 & 0.21 & 0.65 & 0.15 & 0.43 \\
\hline 20 & 0.27 & 0.82 & 0.19 & 0.57 \\
\hline 27 & 0.36 & 1.03 & 0.26 & 0.77 \\
\hline 35 & 0.58 & 1.45 & 0.44 & 1.17 \\
\hline
\end{tabular}

Proc. of SPIE Vol. 10706 107065G-10 


\subsection{LENS 8 (SLAL-9)}

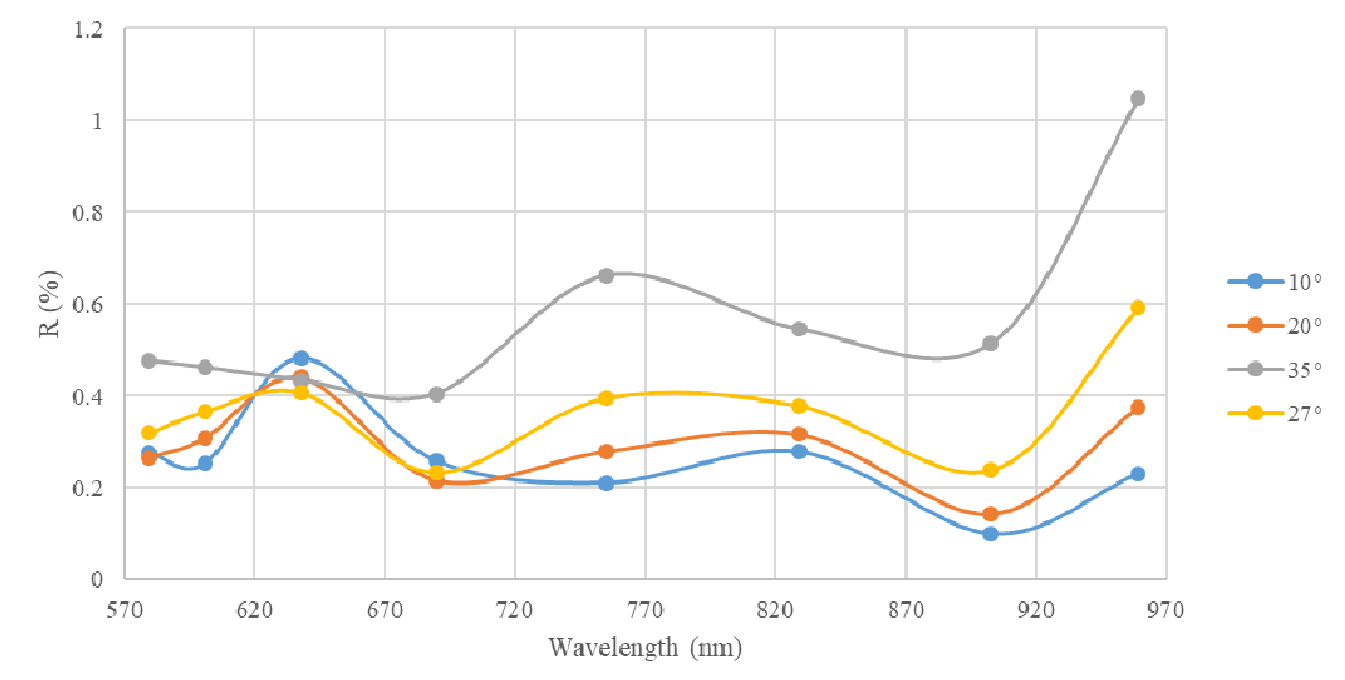

Figure 9. Reflectance obtained for SLAL-9 Lens 8. Surface 1.

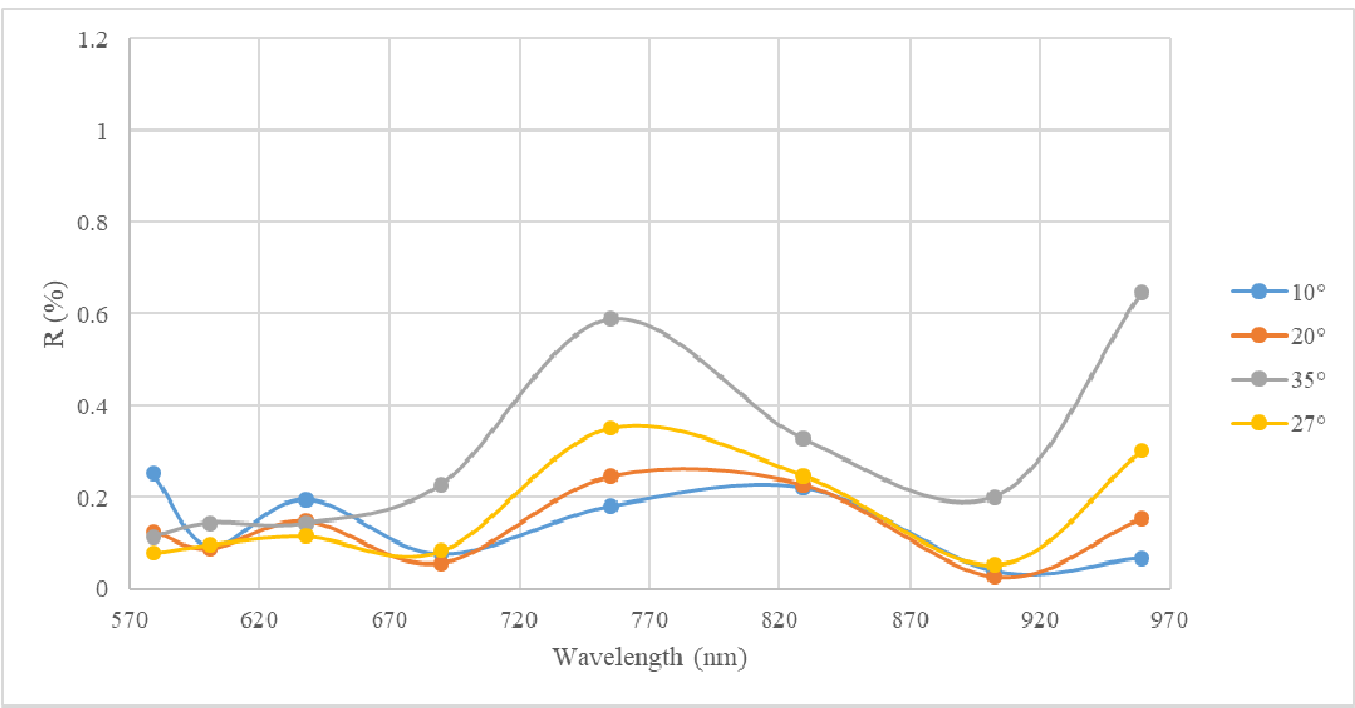

Figure 10. Reflectance obtained for SLAL-9 Lens 8. Surface 2.

Figure 5. Histograms of number of rays hitting the indicated lens surface at different AOI bins

Table 8. Average reflectance obtained for Lens 8.

\begin{tabular}{|c|c|c|c|c|}
\hline \multirow{2}{*}{ AOI } & \multicolumn{4}{|c|}{ Reflectance (\%) } \\
\cline { 2 - 5 } & \multicolumn{2}{|c|}{ Surface 1 } & \multicolumn{2}{c|}{ Surface 2 } \\
\cline { 2 - 5 } & Ave & Max & Ave & Max \\
\hline 10 & 0.26 & 0.50 & 0.15 & 0.32 \\
\hline 20 & 0.26 & 0.48 & 0.14 & 0.25 \\
\hline 27 & 0.29 & 0.44 & 0.13 & 0.25 \\
\hline 35 & 0.57 & 1.05 & 0.30 & 0.65 \\
\hline
\end{tabular}

Proc. of SPIE Vol. 10706 107065G-11 


\section{CONCLUSIONS AND FURTHER WORK}

Great amount of R\&D has been done in the determination of the most suitable material combination and optimal optical properties of AR coatings for the specific case of WEAVE. The requirements are large AOI and a medium size spectral range. Red Camera coatings are soon to be finished and the Blue Camera along with its AR coatings are under development.

\section{REFERENCES}

[1] Dalton, G., et al. "Construction progress of WEAVE: the next generation wide-field spectroscopy facility for the William Herschel Telescope". Proc. SPIE 10702, Paper No. 10702-47 (2018).

[2] Dalton, G., et al., "Final design and progress of WEAVE: the next generation wide-field spectroscopy facility for the William Herschel Telescope," Proc. SPIE 9908, pp. 99081G (2016).

[3] Izazaga, R., et al. "The polishing of WEAVE spectrograph collimator mirror", Proc. SPIE 10706, Paper No. 10706-18 (2018).

[4] Izazaga, R., et al. "WEAVE spectrograph camera: the polishing of the spherical lenses", Proc. SPIE 10706, Paper No. 10706-127 (2018).

[5] Hidalgo, A., et al. "Test plates design and manufacturing for the camera lenses of the WEAVE spectrograph", Proc. SPIE 10706, Paper No. 10706-130 (2018). 